\title{
System Changeover Policy and Precautions
}

\begin{abstract}
In this paper, different changeover policy is discussed. Conversion planning it is essential for system upgradation. Here different traditional up gradation process also discussed. For fast and efficient changeover process, concept of planning, scheduling, procurement process is also discussed in this paper. Different industry in emerging markets became more competitive during the last decade. We attribute the predominantly downward trend in competition to increase their size and the shift from traditional intermediation to off-balance sheet activities. Determination of changeover time is also important for tradeoffs between product quality and profit. Direct changed over, parallel changed over, pilot change over and distributed changeover briefly discussed in this paper.
\end{abstract}

Ashima Banerjee

benefit from the practice of stakeholders' management.

\section{Keywords}

Entrepreneurship;

Changeover,

Conversion;

Innovation and Creativity;

Planning and Scheduling;

\section{INTRODUCTION}

System changeover is concerned with the smooth shift from one way of doing things to another and the mitigation of disruption to business activities during the changeover [1]. The development of an incomplete opportunity definition project in the initial phase of a project's life cycle is a common source of difficulty in the development process [2]. Meanwhile, the development of the project can affect the various positive or negative interests [3]. Especially the construction projects bring different degrees of environmental change and change of people, not limited to construction. Therefore, the project definition may be reset the boundaries, or subject to various expectations and interpretations by different stakeholders [4]. Literature proposes that the project's scope definition practice and stakeholder management are two separate domains, which are often investigated separately. However, the definition of project opportunities may
Using a systematic judgment and participating theory to combine two domains, this research will contribute to the theory and practice in managing the project [5]. The main empirical question: 'How can the level of completeness of the project opportunity are evaluated in the account for the difference between shareholders for the benefit of a better project results among public disaster projects? The research is being conducted to develop a project that will help in the project planning project partnership phase gradually, with adequate consideration of partners' inputs at the planning stage, with the help of measuring the completeness of the project convection, and this will create a better project results [6]. Which maintained the policy of the Global Software Development (GSD) strategies [7] that indicate product quality distribution and organized development and the tools effectively effect the distribution effect of a project in the industry. However, the diversity of the project features and the environment for research [8]. Development industry distribution patterns gradually continued among the most popular methods of investigation, the most preferred methods are the most effective. Our future work will include studying GSD projects in ABB and identifying it Select the GSD-related risk indicators, find and measure them Effect We hope to do more to project managers of the GSD and non-GSD team Effectively and other project managers gain from this knowledge and thereby achieving superior project group performance and good business results.

\section{CONVERSION CONSIDERATIONS AND STRATEGY}

For any particular system, conversion planning it is essential to research about the new system and gathers all information about it. Necessitate other details for the analyst, which includes the following essentially are required. Some important considerations are discussed here.

\section{A. Appointment of Specialized Person}

Appointing an energetic, well experienced manager to supervise, or personally supervising, the preparation of the installation site is essentially required. In order to complete change over, the supervisor must prepare a method of action to complete the change over within the deadline. The manager must prepare a report and 
note regarding the concern conversion [9]. Regular monitoring of the conversion and various risk factors is essential to proper documented. Regular meeting overcome various communication gap and problems. Different strategy like work shift, number of the employee, instruments or equipment which are used to complete the conversion is also necessary to clarify to the management in documented way to avoid future conflict [10]. A track development must be documents in every state, a start-up activity by the individual receiving the board until the final changeover work.

\section{B. Planning and Scheduling}

Planning, scheduling, and supervising programmers and data entry personnel who must convert all significant files and databases [11]. For many implementations, the chief supervisor role will be precisely estimating the time needed for each activity, appointing different people in different section to manage each subproject, and coordinating their assign tasks.

\section{Procurement Process}

Ordering equipment which is required to make the system changeover must be placed at least four months ahead of the planned conversion time. Four month time is sufficient for delivery time in the factory site that at least it reaches before the schedule time. If the delivery time required less it may be order latter. If the items reaches earlier then another problem may arises like that the materials or items may be damaged due to unused. Other problem may be that take care of the system and arrangement of proper security of the items. Space allocation of the new items also another problem.

\section{Possible APProaches for System Changeover}

System Changeover is the process of changing the old system with new one. The System changeover is generally an important method for substituting old system with a new one.

\section{A. Direct Changed Over}

In direct cutover method is a direct approach where any old running system is directly over write by the new one. This approach may cause the system changeover from the older system with a completely new system which starts operation immediately [12]. This method is least expensive method but it has high risk of data loss among all the four possible process. Another major disadvantage is that the old system cannot revert. Direct cutover some time have risks of the total system breakdown and if it occur both the old system and new system not work and complete work of the organization stop its regular work [13]. If any organization have less fund then it may used as high risk is involved.

\section{B. Parallel Changed Over}

Basically in the transaction stage of any new process may be initiated by keeping the old module or system running as parallel operation i.e. side by side. All of the data and information which are used as input into the old system may be used as input into the new system [14]. Results of the new system is verified with old system and also verify the check list which are prepared in the previously. Ultimately, the old system or module is stopped working only the new module work successfully. This is has its advantages If anything goes wrong with the new system, the old system will act as a back-up.

\section{Pilot Changed Over}

The pilot operation is the basic changeover technique which involves the various modules implementing a complete new system at a specific sector of the organization. The group or subgroup those are uses the new modules are called the pilot batch or pilot site [15]. The existing system or old module may continue its operation in the entire institution including its pilot site. If it operate successfully in the pilot site then it implement in the entire new system which may reduces the risk failure. This method is less expensive in compare with the parallel changeover. Modular conversion uses the building of self-contained, operational subsystems to change from old systems to new in a gradual manner. As each module is modified and accepted, it is put into use. One advantage is that each module is thoroughly tested before being used. Another advantage is that users are familiar with each module as it becomes operational. Their feedback has helped determine the final attributes of the system. Object-oriented methodologies often use this approach.

\section{Gradual/Phased Changed Over}

The problems associated with existing system are determined in the previous steps, the analyst can initiate preparation how the proposed system will fix those difficulties and try to convert difficulties into opportunity [16]. The systems analyst prepared a register of task and requirements list with details specifications required for the propose module [17]. Here 'requirements' may be desire targets or aims, which are known as Requirements Specifications. The analyst may require new hardware and software. The analyst may require special input devices like scanners, barcode readers, card readers etc. and also any special output device. Based on their decision type of the 
software like, custom-written software or off-the-shelf software like ready-made type software may be procedures. Off-the-shelf software is developed for use by a wide range of user and may not be system dependent, basically general-purpose and trusted and more reliable for the reason that most troubles will have been faced among the several end-users. Gradual, or phased, conversion attempts to combine the best features of the two previously mentioned plans, without incurring all the risks [18]. In this plan, the volume of transactions handled by the new system is gradually increased as the system is phased in. The advantages of this approach include allowing users to get used to the system gradually, the possibility of detecting and recovering from errors without a lot of down time, and the ability to add features one-by-one. Agile methodologies tend to use this conversion approach.

\section{E. Distributed Changed Over}

In many cases in banking, shopping malls, restaurants or clothing store many installations of the same system are consider [19]. The distributed conversion refers to a situation in which there may be any chances to find error. One entire conversion is done with any of the four approaches considered previously at one site. When that conversion is successfully completed, other conversions are done for other sites. An advantage of distributed conversion is that problems can be detected and contained rather than inflicted simultaneously on all sites. A disadvantage is that even when one conversion is successful, each site will have its own people and culture, along with regional and local peculiarities to work through, and they must be handled accordingly.

Different changeover processes are shown in Fig 1. This figure is just an overview of the different process. Actual timing may be differed due to planning, scheduling, and supervising programmers etc. It helps to decide whether to go ahead with the project or not.

\section{General Practices}

The following general practices may follow in everywhere during the changeover like equipment's in manufacturing, packing area at the manufacturing area, production department etc. Checking is one of the essential practices. The upgraded system work properly may be determined by its expected outcome, if it is not we have found the problem and resolved those issues. Batch to batch changeover or changeover from one batch to another batch of the same product required to check the finishing product quality. For individual equipment, first ensure that the process of the batch on that particular equipment is over or complete and the product is removed and dispatched for further process. It is also essential to remove the residual product. This process is vital in any chemical industry, drug industry to maintain the different composition ratio. Quality Assurance certificate is essential for new product.

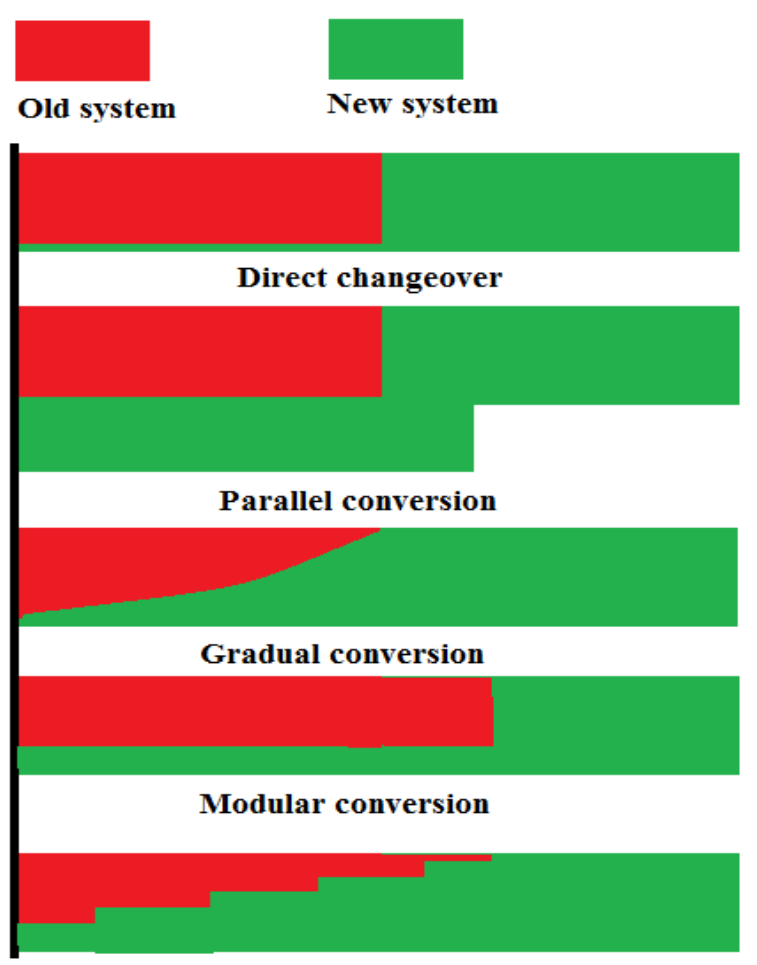

Distributed conversion

Fig 1. Illustration of the different conversion or changeover methods.

\section{Conclusion}

There are three main changeover methods used, phased implementation, direct changeover and parallel running, other two are extended of this. For any smaller projects or organizations conversion and up gradation work by own. Many project management techniques like function point analysis, Gantt charts, PERT are available which are essential for consideration. Successfully communicate with team members, are useful for planning and controlling the whole implementation and change over process.

\section{REFERENCES}

[1] Bigley, G. A., \& Roberts, K. H. (2001). The incident command system: High-reliability organizing for complex and volatile task environments. Academy of Management Journal, 44(6), 1281-1299. 
[2] Atkinson, R., Crawford, L., \& Ward, S. (2006). Fundamental uncertainties in projects and the scope of project management. International journal of project management, 24(8), 687-698.

[3] Kostova, T., \& Zaheer, S. (1999). Organizational legitimacy under conditions of complexity: The case of the multinational enterprise. Academy of Management review, 24(1), 64-81.

[4] Thyssen, M. H., Emmitt, S., Bonke, S., \& KirkChristoffersen, A. (2010). Facilitating client value creation in the conceptual design phase of construction projects: a workshop approach. Architectural Engineering and Design Management, 6(1), 18-30.

[5] Eisenhardt, K. M. (1989). Building theories from case study research. Academy of management review, 14(4), 532-550.

[6] Caplow, S., Jagger, P., Lawlor, K., \& Sills, E. (2011). Evaluating land use and livelihood impacts of early forest carbon projects: Lessons for learning about REDD+. Environmental Science \& Policy, 14(2), 152-167.

[7] Hargreaves, E., Damian, D., Lanubile, F., \& Chisan, J. (2004). Global software development: building a research community. ACM SIGSOFT Software Engineering Notes, 29(5), 1-5.

[8] Amabile, T. M., Conti, R., Coon, H., Lazenby, J., \& Herron, M. (1996). Assessing the work environment for creativity. Academy of management journal, 39(5), 1154-1184.

[9] Mukherjee, M. (2017). Function of Project Manager and Officer. International Journal of Advanced Engineering and Management, 2(8), 180-182.

[10] Glendon, A. I., \& Litherland, D. K. (2001). Safety climate factors, group differences and safety behaviour in road construction. Safety science, 39(3), 157-188.

[11] Singhal, G. \& Roy, S.(2017). A Survey on Data Clustering, International Journal of Advanced Engineering and Management, 2(8), 183-188.

[12] Bollinger, T. (2001). Managing Technical Change in Legacy Systems. Annals of Software Engineering, 11(1), 237-257.

[13] Shields, M. G. (2004). E-business and ERP: Rapid implementation and project planning. John Wiley \& Sons.
[14] Parnas, D. L. (1972). On the criteria to be used in decomposing systems into modules. Communications of the ACM, 15(12), 1053-1058.

[15] Fret, J., L. Roef, R. Blust, L. Diels, S. Tavernier, W. Vyverman, and M. Michiels. Reuse of rejuvenated media during laboratory and pilot scale cultivation of Nannochloropsis sp. Algal Research 27 (2017): 265-273.

[16] Hollnagel, E. (1993). The phenotype of erroneous actions. International Journal of Man-Machine Studies, 39(1), 1-32.

[17] Roy, A., \& Mukherjee, K. (2017). Entrepreneurial Education in India. International Journal of Advanced Engineering and Management, 2(1), 15-20.

[18] McCarthy, T. M., \& Golicic, S. L. (2002). Implementing collaborative forecasting to improve supply chain performance. International Journal of Physical Distribution \& Logistics Management, 32(6), 431-454.

[19] Bhatt, G. D. (2001). Knowledge management in organizations: examining the interaction between technologies, techniques, and people. Journal of knowledge management, 5(1), 68-75.

Author

Ashima Banerjee

Dept. of Commerce,

Rampurhat College, India

Email:pieuashima@gmail.com 